\title{
O FINANCIAMENTO DO ESPORTE E DO LAZER PELOS MUNICÍPIOS DO ESTADO DO MATO GROSSO DE 2005 A $2008^{1}$
}

Recebido em: 19/09/2017

Aceito em: 14/08/2018

\author{
Edmilson Santos dos Santos ${ }^{2}$ \\ Universidade Federal do Vale do São Francisco (UNIVASF) \\ Petrolina - PE - Brasil \\ Fernanda Gimenez Milani ${ }^{3}$ \\ Universidade Estadual do Maringá \\ Maringá - PR - Brasil \\ Riller Silva Reverdito ${ }^{4}$ \\ Universidade do Estado de Mato Grosso \\ Cárceres - MT - Brasil \\ Fernando Augusto Starepravo 5 \\ Universidade Estadual do Maringá \\ Maringá - PR - Brasil
}

RESUMO: A Constituição Federal de 1988 não garantiu que as políticas de esporte e de lazer compusessem o rol de competências dos municípios. Nesse sentido, há de perspectivar a inação como um comportamento possível dos gestores municipais no que tange ao financiamento do esporte e do lazer. Nesse sentido, o presente estudo de natureza descritivo exploratório buscou analisar o comportamento das prefeituras do estado do Mato Grosso no que concerne ao financiamento do esporte e do lazer na Função Desporto e Lazer (FDL), e apresenta, como objetivos específicos analisar qual a participação dos municípios no estado do Mato Grosso no financiamento da FDL e analisar o financiamento da FDL por níveis da classe populacional e desenvolvimento humano. Os resultados indicam que as prefeituras do estado do Mato Grosso, no ciclo eleitoral 2005/08, preferem o investimento da FDL a inação.

\footnotetext{
${ }^{1}$ A pesquisa que resultou neste artigo contou com o financiamento da Rede CEDES/ Ministério do Esporte.

2 Doutorado em Ciências do Movimento Humano pela Universidade Federal do Rio Grande do Sul

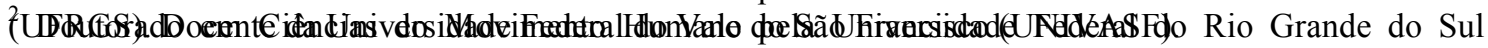
(UFRGS). Docente da Universidade Federal do Vale do São Francisco (UNIVASF).

${ }^{3}$ Mestranda em Educação Física pela Universidade Estadual de Maringá (UEM). Integrante do Grupo de Estudo e Pesquisa em Políticas Públicas de Esporte e Lazer (GEPPOL).

${ }^{4}$ Doutor em Educação Física pela Universidade Estadual de Campinas (FEF/UNICAMP). Docente na Faculdade de Ciências da Saúde, curso de Educação Física, da Universidade do Estado de Mato Grosso (FACIS/UNEMAT).

5 Doutor em Educação Física pela Universidade Federal do Paraná (UFPR). Docente da Universidade Estadual de Maringá (UEM).
} 
PALAVRAS CHAVE: Política Pública. Financiamento Governamental. Esportes.

\section{SPORT AND LEISURE FINANCING BY MUNICIPALITIES IN THE STATE OF MATO GROSSO FROM 2005 TO 2008}

ABSTRACT: The 1988 Federal Constitution has not guaranteed sport and leisure policies to be part of the range of municipalities' competencies. For that matter, it is important to set a perspective on the ination as a possible behavior of municipal governments regarding financing of sport and leisure. Thus, the present descriptive and exploratory study aimed to analyze the behavior of municipal governments in the state of Mato Grosso concerning financing of sport and leisure in the Sport and Leisure Function (SLF), and it presents as specific goals to analyze the participation of such municipalities in the financing of SLF and to observe the financing of SLF by populational and human development levels. Results indicate that municipalities in the state of Mato Grosso, during the electoral cycle 2005/2008, prefer the investment in the SLF than the ination.

KEYWORDS: Public Policy. Financing, Government. Sports.

\section{Introdução}

O debate em torno das políticas públicas tem ganhado relevo na literatura na área de educação física nos últimos anos. Parte significativa desse debate tem sido fomentada pelo papel de destaque do governo federal no financiamento do esporte brasileiro e pela criação de estrutura político-administrativa, em nível de primeiro escalão, para sua gestão, o Ministério do Esporte.

No entanto, parte importante do financiamento do esporte e do lazer tem sido efetivada por outra instância federativa, os municípios. Dentre as 28 federações existentes no mundo, a federação brasileira é a mais descentralizada e a única formada por três entidades federadas com possibilidade de implementarem políticas públicas de forma autônoma: União, estados e Distrito Federal e municípios (CATAIA, 2011; ARRETCHE, 2003, 2004, 2010; PRADO, 2001).

No ano de 2004, os dois principais programas sociais do Governo Federal na área esportiva, Programa Segundo Tempo (PST) e Programa Esporte e Lazer da Cidade 
(PELC), foram responsáveis por um investimento no valor de $\mathrm{R} \$ 178.610 .000,00$. Foram investidos R\$45.480.000,00 no PST e R\$ 133.130.000,00 no PELC (CASTRO, 2016). O investimento da União correspondeu a $12,03 \%$ do que foi investido pelos municípios no ano de 2004 na Função Desporto e Lazer (FDL): R\$ 1.106.829.332,76. Ou seja, no ano de 2004, o ente federado mais próximo do cidadão já era responsável pela maior parcela de investimento em políticas públicas de esporte e de lazer. Em 2010, o Ministério do Esporte investiu R\$ 714.690.000,00 no PST e PELC. Já os municípios investiram R\$2.108.666.140,60. O Governo Federal acabou ampliando sua participação no financiamento do esporte, passando de $12,03 \%$ para $33,89 \%^{6}$, mas mesmo assim os municípios continuaram tendo papel central na implementação de políticas públicas de esporte e lazer.

Apesar de serem responsáveis pela maior parcela do investimento, os municípios são atores periféricos do ponto de vista da análise de políticas públicas ${ }^{7}$. Poucos são os trabalhos que focam a análise no desempenho dessa esfera federativa. No entanto, diante da magnitude dos investimentos aqui apresentados, essa lacuna compromete uma compreensão mais adequada da implementação de políticas públicas de esporte e lazer no Brasil.

Como já destacado, o gasto social realizado na Função Desporto e Lazer, por parte dos municípios, ainda não foi explorado de forma a compreendermos melhor sua distribuição e níveis diferenciados de investimentos. Diante dessa realidade, o estudo

\footnotetext{
${ }^{6}$ Para efeito dessa análise foram considerados apenas o PST e PELC, pelo Governo Federal, e o financiamento dos municípios pela FDL, por parte dos municípios.

${ }^{7}$ O papel dos municípios na descentralização de políticas nacionais tem sido alvo de alguns trabalhos, como Reverdito et al. (2016), Santos e Nogueira (2016), Santos; Starepravo e Souza Neto (2015), Santos; Andrade e Santos (2014), Santos (2013) e Santos (2012).
} 
caracteriza-se por ser quantitativo e descritivo de cunho exploratório ${ }^{8}$ (GIL, 2007) e teve como objetivo central analisar os investimentos dos municípios do estado do Mato Grosso na FDL referentes ao ciclo eleitoral 2005/2008.

Elegemos a escala municipal, pois é aquela ainda pouco explorada na literatura da área da educação física e esporte que analisa o financiamento das políticas públicas de esporte e lazer dos municípios. Além disso, como entes federados, municípios possuem autoridade política para fazer escolhas (preferências alocativas) sobre os recursos disponíveis em seus orçamentos.

Para tanto, elaboramos os seguintes objetivos específicos: (a) analisar qual a participação dos municípios no estado do Mato Grosso no financiamento da FDL; (b) analisar o financiamento da FDL por níveis de classe populacional e desenvolvimento humano.

\section{O Esporte e o Lazer no Texto Constitucional}

O esporte e o lazer assumem, pela primeira vez na história do Brasil, papel de destaque no ordenamento jurídico constitucional brasileiro na Constituição Federal de 1988 (BRASIL, 1988). O esporte assume designação específica no Título VIII - Da Ordem Social, no Capítulo III - Da Educação, Da Cultura e do Desporto, na Seção III Do Desporto, Art. 217. Já o lazer não teve concertação política capaz de incluí-lo como seção. Por ser portador de interesses difusos, não vinculado a um determinado grupo de interesse, e abrigar diferentes áreas (educação física, cultura, turismo, por exemplo), o tema não pode ser privilegiado. O trabalho de Santos (2014) faz um relato detalhado da

\footnotetext{
${ }^{8}$ As pesquisas descritivas de cunho exploratório são classificadas com base em seus objetivos descreverem características ou fenômenos (pouco conhecidos) de determinada população com vistas a constituir hipóteses e aprimorar ideias (GIL, 2007).
} 
trajetória do lazer na Assembleia Nacional Constituinte de 1987. Mesmo assim, o lazer vai aparecer topicamente no Art. 6 e no Art. 227 da Constituição Federal de 1988.

Estar presente no texto constitucional representa um importante avanço no sentido de sinalizar claramente à sociedade o grau de importância que está sendo dado a uma determinada agenda política. Porém, não significa a aplicabilidade direta dos preceitos nele contidos (GOMES, 2010; SANTOS; FREITAS, 2015). Num estado federalista, é preciso apontar claramente, no texto constitucional ou em normas advindas do poder legislativo federal, as funções que devem desempenhar cada um dos entes federados. O direito precisa estar alinhado com o dever para que possa se efetivar.

O debate em torno do direto ao esporte e ao lazer tem ficado preso às análises do princípio instrutivo da norma. O texto do Art. 217, em seu caput, afirma que "É dever do Estado fomentar práticas desportivas formais e não-formais, como direito de cada um” (BRASIL, 1988). Apenas é traçado um esquema geral e não há indicação de como esse direito irá se manifestar. Ou seja, o Estado brasileiro apontou o direito, mas não atribuiu responsabilidades à sua efetivação.

Diferentemente do esporte, o lazer aparece como direito social explicitado no texto do Art. 6. Teve abrigo também no Art. 227 do Capítulo VII - Da Família, Da Criança, Do Adolescente, Do Jovem e Do Idoso:

É dever da família, da sociedade e do Estado assegurar à criança, ao adolescente e ao jovem, com absoluta prioridade, o direito à vida, à saúde, à alimentação, à educação, ao lazer, à profissionalização, à cultura, à dignidade, ao respeito, à liberdade e à convivência familiar e comunitária, além de colocá-los a salvo de toda forma de negligência, discriminação, exploração, violência, crueldade e opressão (BRASIL, 1988). 
Cabe ressaltar que, diferentemente do esporte, a Constituição Federal de 1988 compartilhou o dever com as famílias e com a sociedade. Sendo assim, o Estado não responde de forma solitária e compulsória a essa agenda.

Nos dois casos, por motivos distintos, o texto não tem o poder de produzir eficácia aplicativa da norma (Norma de Eficácia Limitada) ${ }^{9}$. Nesse caso, ela é dependente do que está disposto nos artigos 21, 22, 23, 24, 25 e 30 da Constituição Federal de 1988 ou de lei infraconstitucional capaz de melhor orientar as responsabilidades de cada ator na garantia do direito. Na área de políticas públicas de esporte e lazer esse debate tem sido feito no sentido de transformar as políticas governamentais em políticas de Estado. Ou seja, produzir o arcabouço normativo à aplicação das normas presentes no Art. 217 e Art. 6.

O Estado Democrático de Direito se expressa e tem como base para o seu entendimento o texto constitucional. A garantia de aplicação do texto é a proteção ao Estado Democrático de Direito. Nesse sentido, é imprescindível incorporarmos à análise o federalismo brasileiro. É através dele que podemos conhecer as competências estabelecidas para cada um dos entes federados (HORTA, 1991; MUKAI, 2001).

Como sabemos, são duas instituições responsáveis pela implementação de políticas públicas que permitem a efetivação do direito: o poder executivo e o poder legislativo. A técnica legislativa operada no texto constitucional tratou em artigos diferentes a competência para legislar e a competência para administrar (MACHADO, 1996). A Constituição Federal 1988 conferiu diferentes comportamentos a esses atores institucionais no que se refere aos temas esporte e lazer. É na definição das funções que

\footnotetext{
${ }^{9}$ As Normas de Eficácia Limitada atuam em oposição às Normas de Eficácia Plena. Nesse último caso, a aplicação é imediata, não necessitando de lei para garantir sua aplicação, como no Inciso I do Art. 217 (GOMES, 2010).
} 
cada um tem diante das políticas públicas que podemos compreender seus papéis na efetivação do direito.

A leitura isolada do Art. 217 não responde adequadamente à complexidade do texto constitucional. Até porque, ela não indica nenhuma responsabilidade além de fomentar as práticas esportivas. Algo que pode ser alcançado apenas com uma campanha publicitária, por exemplo, e não é isso que a sociedade espera de uma política social.

Sendo atores governamentais do processo de políticas públicas os poderes executivo e legislativo (SECCHI, 2013), necessário se faz percorrer as prescrições contidas na norma constitucional buscando observar as responsabilidades atribuídas a eles enquanto componentes da Federação. Isso remete à análise do Título III - Da Organização do Estado. Já o Art. $18^{10}$, introdutório, indica que a organização políticoadministrativa da República Federativa se dá nos termos da constituição e elege seus integrantes: União, estados, Distrito Federal e Municípios ${ }^{11}$ (BRASIL, 1988).

As proposições acerca do comportamento a ser seguido pelos entes federados começam a ser descritas no Art. 21 (Competências da União). Para Horta (1991, p. 249), “A repartição de competências é exigência da estrutura federal de Estado, para assegurar o convívio dos ordenamentos que compõem o Estado Federal". No que concerne ao poder executivo, não compete à União, de forma exclusiva, o compromisso com as políticas de esporte e de lazer. Em competências exclusivas, presente no Art. 30, também não aparece nenhuma menção com relação aos municípios. E deixa em aberto

\footnotetext{
${ }^{10}$ Art. 18. A organização político-administrativa da República Federativa do Brasil compreende a União, os Estados, o Distrito Federal e os Municípios, todos autônomos, nos termos desta constituição.

${ }^{11}$ Com relação à incorporação do Município como o terceiro ente federado, essa é uma inovação institucional não seguida pelas outras federações. Como destaca Mukai (2001), nenhuma outra nação reconhece o município como peça do regime federativo.
} 
para os estados no parágrafo primeiro do Art. 25 e ao Distrito Federal no parágrafo primeiro do Art. 32.

No que concerne ao esporte e ao lazer, estes também não aparecem no Art. 22, no que diz respeito às competências legislativas privativas à União. Não está colocado que o poder legislativo federal deve ser responsivo de forma privativa com relação às políticas públicas de esporte e de lazer. Ou seja, o que está posto no ordenamento jurídico que funda nosso Estado Democrático de Direito é que a União não tem compromissos solitários (privativos) com essas duas agendas, nos âmbitos administrativos e legislativos.

Não sendo de competência da União, o outro plano se refere à Competência comum da União, dos Estados, do Distrito Federal e dos Municípios prevista no Art. 23. As competências comuns inauguram o aspecto cooperativo do federalismo brasileiro. Para Bercovici (2011) e Ferraz Jr. (1995), a virtude cooperativa exprime o verdadeiro sentido da federação, buscar a equidade, presente no Inciso III do Art. 3 e permite a superação das desigualdades regionais.

A análise à luz da Constituição de 1988, portanto, revela que o grande objetivo do federalismo é a busca da cooperação entre União e entes federados, equilibrando a descentralização federal com os imperativos da integração econômica nacional (BERCOVICI, 2011, p. 8).

Uma crítica importante estabelecida por Horta (1991) é a descaracterização promovida pelo parágrafo único do Art. 23. Lá está exposto que: “Lei complementar fixará normas para a cooperação entre União e os Estados, o Distrito Federal e os Municípios, tendo em vista o equilíbrio do desenvolvimento e do bem-estar em âmbito nacional". Transfere para lei complementar algo que só poderia ser estabelecido pelo texto constitucional: encargos dos estados e municípios. Por outro lado, o pacto 
federativo necessita de um agente coordenador e do ambiente onde ele possa estar constitucionalmente autorizado a operar (BERCOVICI, 2011).

O estado federativo brasileiro é marcado por severas discrepâncias socioeconômicas. Nesse sentido, é importante que a União tenha capacidade de coordenar ação política que leve ao fortalecimento da federação, como determinado no Inciso III do Art. 3 (KLEINKE et al., 2009; ALMEIDA, 1995; ARRETCHE, 2010). Para isso, é necessário que se garanta a possibilidade de agirem de forma cooperada, pois, segundo nosso arranjo federativo, somente através da cooperação será possível diminuir desigualdades, algo inalcançável com competências privativas de entes subnacionais (ARRETCHE, 2010).

No Art. 23, estão as competências administrativas comuns da União, dos Estados, do Distrito Federal e dos Municípios. Não está previsto que os entes federados devam ser responsivos a essas agendas. Porém, é no Art. 24 que os constituintes começaram a desenhar o grau de responsabilidade dos entes federados com relação ao esporte (o texto é omisso em relação ao lazer).

Ele vai aparece no plano da Competência de legislação concorrente da União, dos Estados e do Distrito Federal. A primeira ressalva é que no Art. 24 não foi elencado o município como esfera de aplicação da competência legislativa concorrente. Uma diferença doutrinária apontada por Bercovici (2011, p. 3) é que, mesmo não constando no Art. 24, eles estão à margem das competências concorrentes, tendo em vista o que está “[...] disposto no artigo 30, II da Constituição, que dá competência aos Municípios para legislarem de maneira suplementar no que lhes couber.”.

Para Mukai (2001), essa exclusão foi proposital. A base da subtração está em que haveria diferenças substantivas entre as competências administrativas e legislativas. 
Porém, o Inciso I do Art. 30 permite que ele possa agir de forma complementar à legislação federal.

A única hierarquia existente na competência concorrente é esta: o município, na sua legislação, terá que observar as normas gerais válidas da União e dos estados; estes terão que observar, não podendo contrariar, as normas gerais dirigidas aos particulares, da União (MUKAI, 2001, p. 92).

No Inciso IX está expresso que compete aos entes federados, de forma concorrente, atuarem no esporte. Isso significa que cabe aos legislativos, através de leis ordinárias, estabelecerem os compromissos do poder executivo com essa agenda. A ideia central é que a autonomia e a responsividade em relação às demandas da população fizessem com que os poderes legislativos fossem pressionados a produzirem, de forma concorrencial, a qualificação em escala da legislação sobre o esporte.

A aplicação do direito ao esporte, especificamente, e não ao lazer, deve ser respondida não por uma atuação do poder executivo, mas, sim, do poder legislativo. Portanto, não cabe a cobrança aos poderes executivos nacional, estaduais e municipais da garantia do direito ao esporte, se eles devem ser responsivos, segundo o Estado Democrático de Direito, a existência de norma conforme o parágrafo único do Art. 23.

A liberdade de organização administrativa dos entes federados permite a constituição de um cenário mais ativo em relação às políticas de esporte e de lazer. Nos três entes federados é possível ver iniciativas de criação de órgãos de primeiro escalão para implementar políticas públicas de esporte, especialmente, e de lazer. Nesse caso, temos então a descentralização bottom-up, que é quando o município implementa sua 
própria agenda política ${ }^{12}$. No entanto, na escala municipal há uma carência de estudos apontando a forma como a agenda política dos prefeitos se organiza para lidar com o esporte e o lazer. Encontramos na literatura o trabalho de Santos; Canan e Starepravo (2018) que analisaram o gasto na FDL no estado da Bahia. Diante da não obrigatoriedade, é razoável apontarmos que os municípios tenderão à inação a ampliar os gastos sociais.

\section{Metodologia}

Para análise pretendida optamos por utilizar as bases de dados que possuem informações sobre os municípios brasileiros. Elas compõem banco de dados produzido pelo Centro de Desenvolvimento de Pesquisas em Políticas Públicas de Esporte e Lazer da Rede Cedes Piauí ${ }^{13}$. As informações referentes ao número de municípios do estado e suas características demográficas foram coletados no banco de dados sobre as cidades, disponível no site do Instituto Brasileiro de Geografia e Estatística (IBGE) ${ }^{14}$. O nível de desenvolvimento humano foi aferido com base no índice produzido pelo Programa das Nações Unidas para o Desenvolvimento (PNUD) ${ }^{15}$.

A Função Desporto e Lazer representa o maior nível de agregação dos gastos públicos realizado pelos municípios. Ela está organizada de forma a contemplar gastos

\footnotetext{
12 A descentralização de implementação top-down (descentralização top-down) é quando o município descentraliza política definida (formulada e financiada) por um ente federado superior. Na implementação bottom-up (descentralização bottom-up), a formulação, o financiamento e a implementação ocorrem sob a responsabilidade do ente federado subnacional (estados, Distrito Federal, município). Para melhor análise do modelo, ver Sabatier (1985).

${ }^{13}$ Centro de Desenvolvimento de Pesquisas em Políticas Públicas de Esporte e Lazer da Rede Cedes Piauí é formado pelo Grupo de Estudos e Pesquisas em Políticas Públicas de Esporte e Lazer da Universidade Federal do Vale do São Francisco. Sua implementação se deu através de Chamada Pública, em 2015, para seleção para apoio à estruturação e ao funcionamento dos "Centros de Desenvolvimento de Pesquisas em Políticas de Esporte e de Lazer da Rede Cedes" financiada pela Secretaria Nacional De Esporte, Educação, Lazer e Inclusão Social - SNELIS/Ministério do Esporte.

${ }^{14}$ Disponível em: http://www.cidades.ibge.gov.br/v3/cidades/home-cidades. Acesso em: 20/03/2017.

${ }^{15}$ Disponível em: http://www.br.undp.org/content/brazil/pt/home/idh0.html. Acesso em: 20/03/2017.
} 
de quatro áreas de atuação governamental, chamadas de subfunções (BRASIL, 1999). A especificidade da ação é que orienta a classificação do gasto na subfunção. Temos a subfunção Desporto Comunitário (sDC), a subfunção Desporto Rendimento (sDR), a subfunção Lazer (sL) e a subfunção Outras Subfunção do Desporto e Lazer (sO). As informações referentes à FDL foram capturadas diretamente do site do Tesouro Nacional $^{16}$, nos dados referentes às contas anuais no Sistema de Informações Contábeis e Fiscais do Setor Público Brasileiro - SICONFI ${ }^{17}$.

A análise foi realizada com base na execução orçamentária e não em sua dotação. Importante ressaltar que o orçamento público no Brasil tem caráter autorizativo. Sendo assim, os governos não são obrigados a executar as despesas previstas na Lei Orçamentária Anual (LOA). No presente estudo trabalhamos com a liquidação do gasto na FDL. Ou seja, aquilo que o gestor foi capaz de implementar em termos de políticas públicas ${ }^{18}$.

Para análise do impacto do tamanho dos municípios no financiamento da FDL, assumimos nesse trabalho a classificação populacional do IBGE: (CP1) cidades até 4.999 habitantes; (CP2) entre cinco mil e 9.999 habitantes; (CP3); entre 10 mil e 19.999 habitantes; (CP4) entre 20 mil e 49.999 habitantes; (CP5) entre 50 mil e 99.999 habitantes; (CP6) entre 100 mil e 499.999 habitantes; (CP7) acima de 500 mil habitantes. As informações serão tomadas com base no censo de 2010 realizado pelo Instituto.

\footnotetext{
${ }^{16}$ Disponível em: https://siconfi.tesouro.gov.br/siconfi/pages/publi. Acesso em: 20/03/2017.

${ }^{17}$ Anualmente as prefeituras apresentam as informações contábeis conforme Lei $\mathrm{n}^{\circ} 4.320$, de março de 1964 (BRASIL, 1964), e artigo 51 da Lei de Responsabilidade Fiscal (BRASIL, 2000).

${ }^{18}$ As diferenças em relação aos "n" em cada ano de investigação se deve pelo fato que as declarações financeiras dos municípios no relatório do SICONFI não são uniformes.
} 
A análise dos níveis de desenvolvimento humano foi realizada com base na seguinte classificação do IDH: Muito Baixo zero até 0,499 ; Baixo de 0,500 a 0,599; Médio de 0,600 a 0,699; Alto de 0,700 a 0,799; Muito Alto acima de 0,800.

A análise quantitativa buscará organizar os dados em médias, medianas, desvio padrão e os valores percentuais. Os quadros analíticos serão interpretados a partir dos valores totais e per capita.

\section{Análise dos Resultados}

No período analisado, as prefeituras do Mato Grosso investiram R\$ 101.284.207,01. No mesmo período o Governo Federal descentralizou para o estado R\$ 17.840.000,00 (CASTRO, 2016). Isso significa que os municípios do estado são responsáveis por $82,38 \%$ dos recursos destinados às políticas públicas de esporte e do lazer. Ou seja, são os municípios os maiores financiadores do esporte e do lazer no Mato Grosso, quando comparado com o desempenho do Governo Federal. A despeito de estruturas federativas com funções comuns induzirem a um comportamento oportunista, deixar que outro ente oferte a política, os municípios do estado têm demonstrado postura ativa em relação a essa agenda.

Apenas 2,84\% dos municípios $(n=4)$ não fizeram nenhum investimento na FDL. São eles General Carneiro, Indiavaí, Novo Mundo e Rondolândia. Como podemos perceber, são todas cidades de pequeno porte, até 10 mil/habitantes. Mesmo não estando obrigados a implementar políticas de esporte e lazer, os municípios do estado descentralizaram a função. Talvez esse resultado explique a baixa descentralização das políticas do Governo Federal. 
Como pode ser observado na Tabela 1 , houve variação no grau de adesão dos municípios no financiamento da FDL. Mesmo assim, o grau de adesão à agenda foi sempre superior a $80 \%$. Esse resultado revela uma efetiva descentralização das políticas públicas de esporte e de lazer no estado. Não através da descentralização de políticas do ente federado superior, Governo Federal, mas através da descentralização da função. Isso revela que a onda municipalista promovida pela Constituição Federal de 1988 alcançou as políticas públicas de esporte e de lazer neste estado.

Tabela 1: Evolução da participação dos municípios no financiamento da FDL.

\begin{tabular}{ccc}
\hline Período Analisado & Número de municípios & \% de Participação na FDL \\
\hline 2005 & 113 & 80,14 \\
2006 & 129 & 91,49 \\
2007 & 125 & 88,65 \\
2008 & 128 & 90,78 \\
\hline
\end{tabular}

Fonte: SICONFI

O volume de recursos destinados às políticas públicas de esporte e de lazer tiveram crescimento absoluto durante todo o período analisado (Tabela 2). Os investimentos duplicaram em quatro anos, passando de $\mathrm{R} \$ 20$ milhões para $\mathrm{R} \$ 41$ milhões, um acrescimento no investimento da ordem de 105,08\%. O maior percentual do gasto se deu no último ano dos governos. Esse resultado pode indicar que o aumento em políticas públicas de esporte e lazer pode ter um impacto positivo na avaliação dos governos municipais.

Tabela 2: Evolução do financiamento dos municípios na FDL.

\begin{tabular}{cc}
\hline Período Analisado & Volume de recursos designados a FDL (R\$) \\
\hline 2005 & $20.214 .006,77$ \\
2006 & $26.786 .940,72$
\end{tabular}




\begin{tabular}{cc}
2007 & $30.667 .367,67$ \\
2008 & $41.455 .891,85$ \\
\hline Total & $\mathbf{1 1 9 . 1 2 4 . 2 0 7 , 0 1}$ \\
\hline
\end{tabular}

Fonte: SICONFI

A quantidade de recurso total disponível variou bastante entre as classes populacionais, como indica a Tabela 3. Apesar de ter o menor ' $n$ ' entre as quatro primeiras classes populacionais, as cidades entre 20 e 50 mil habitantes (CP4) foram as que obtiveram o maior volume de recursos investidos na FDL. A distribuição dos recursos segue um padrão aleatório. Não é possível perceber qualquer relação direta entre classe populacional e volume total de recurso, média ou mediana. No entanto, a análise da média indica que o tamanho da população passa a impactar na média per capita.

Tabela 3: Distribuição do financiamento na FDL por Classe de População (CP).

\begin{tabular}{c|ccc|c|c|c|}
\hline \multirow{2}{*}{ CP (n) } & \multirow{2}{*}{ \% Desc* } & \multirow{2}{*}{ Total (R\$) } & \multicolumn{4}{|c}{ Per capita } \\
\cline { 4 - 7 } & & & Méd (DP) & Md & Menor valor & Maior valor \\
\hline $1(36)$ & 94,44 & $9.330 .218,90$ & $15,16(15,38)$ & 10,99 & 0,58 & 88,69 \\
$2(31)$ & 93,54 & $8.656 .910,62$ & $10,31(10,70)$ & 7,40 & 0,14 & 56,92 \\
$3(45)$ & 100 & $34.679 .838,06$ & $13,65(8,96)$ & 12,81 & 1,03 & 35,20 \\
$4(20)$ & 100 & $36.095 .470,23$ & $14,71(11,17)$ & 11,51 & 3,13 & 49,99 \\
$5(5)$ & 100 & $11.439 .766,89$ & $8,70(2,63)$ & 9,21 & 3,22 & 11,15 \\
6 e 7(4) & 100 & $18.922 .002,31$ & $7,51(6,16)$ & 7,51 & 0,30 & 16,03 \\
\hline
\end{tabular}

Fonte: SICONFI; IBGE. *Percentual de descentralização.

Um dado emblemático da tabela 3 diz respeito à adesão dos municípios no investimento da FDL. Nas cidades acima de 10 mil habitantes (a partir da CP3), todos os municípios fizeram investimentos na FDL. A despeito da inexistência de norma específica apontando a necessidade de intervenção, os municípios têm sido ativos na implementação de políticas públicas de esporte e de lazer. Há a efetiva descentralização das políticas públicas de esporte e de lazer no estado do Mato Grosso. 
A descentralização bottom-up é uma realidade no Mato Grosso. Apesar da inexistência de norma de 'Estado', as sociedades locais têm conseguido garantir investimentos importantes na FDL. O ritmo da descentralização das políticas de esporte e lazer aponta para maior responsabilização do poder público municipal, resultado compatível com o esperado pela literatura federalista (ABRUCIO; FRANZESE, 2007). Isso não quer dizer que ela tenha promovido acesso universal às políticas públicas de esporte e de lazer, pois o desenho metodológico não permite essa avaliação.

As cidades de menor nível de desenvolvimento humano, IDH Baixo (2), apresentaram maiores níveis de investimentos na $\mathrm{FDL}^{19}$. As cidades de IDH Alto (4) apresentaram o menor desvio padrão, demonstrando haver maior homogeneidade no comportamento dos municípios, e os segundos valores em termos de média e mediana (Tabela 4).

Tabela 4: Distribuição do financiamento na FDL por IDH.

\begin{tabular}{ccc|cccc}
\hline \multirow{2}{*}{ IDH } & \multirow{2}{*}{$\mathbf{N}^{\mathbf{*}}$} & \multirow{2}{*}{ Total (R\$) } & \multicolumn{4}{|c}{ Per capita } \\
\cline { 4 - 7 } & & Méd (DP) & Md & Maior valor & Menor valor \\
\hline 1 & - & - & - & - & - & - \\
2 & 3 & $872.295,21$ & $22,15(21,83)$ & 15,19 & 1,03 & 57,19 \\
3 & 85 & $44.084 .115,98$ & $15,20(16,58)$ & 9,23 & 0,14 & 88,69 \\
4 & 49 & $74.167 .795,82$ & $15,89(11,86)$ & 12,72 & 0,30 & 56,91 \\
5 & - & - & - & - & - & - \\
\hline
\end{tabular}

Fonte: SICONFI; PNUD.

No que diz respeito aos investimentos por níveis de IDH, não é possível identificar um vetor de investimento da FDL. O IDH Baixo garante médias, medianas e maior valor mais altos. Mas eles não decrescem com o aumento do IDH. Ou seja, não há relação entre níveis de IDH e investimentos na FDL.

${ }^{19}$ Cabe destacar que a literatura sobre federalismo aponta os municípios menores como os maiores beneficiários da redistribuição das transferências governamentais. Para essa análise, ver Gomes e Dowell (2000), Soares e Melo (2016) e Almeida (1995). 


\section{Conclusão}

Os resultados apresentados nesse estudo são reveladores do papel desempenhado pelos municípios no financiamento das políticas públicas de esporte e lazer no Brasil. Quando comparado com os investimentos realizados pelo Governo Federal em suas duas principais políticas sociais, Programa Segundo Tempo e Programa Esporte e Lazer da Cidade, os municípios do estado do Mato Grosso apresentam maiores níveis de investimento.

O segundo aspecto a ser considerado diz respeito à participação dos municípios no financiamento da FDL. Há efetiva descentralização (bottom-up) das políticas públicas de esporte e lazer no estado. Esses dados contrastam bastante com o que é esperado em um federalismo no qual a agenda esportiva e de lazer, especialmente o primeiro, não aparece no rol das competências municipais. O resultado esperado é a inação diante da não obrigatoriedade de investimento. Mas a descentralização das políticas públicas de esporte e de lazer já é uma realidade no Mato Grosso, independentemente do que está previsto no texto constitucional. As prefeituras preferem o financiamento da FDL à inação.

Os valores per capita envolvidos no investimento na FDL por classe populacional indicam que as maiores cidades têm maiores dificuldades de manter os níveis alcançados pelas cidades de menor porte. Isso significa que o tamanho da cidade impacta na quantidade de recursos disponíveis por habitantes.

Outro fato revelador está na análise do investimento dos municípios por IDH. Cidades com menores IDH apresentaram maiores investimentos. Porém, o resultado da análise do IDH indica que o município não determina os níveis de investimentos na 
FDL. As desigualdades socioeconômicas não impactam na distribuição de políticas públicas municipais de esporte e de lazer.

O federalismo suporta níveis diferenciados de investimento em políticas públicas, pois aponta as prioridades alocativas dos detentores do poder local. No entanto, outras variáveis podem atuar nessa realidade como, por exemplo, filiação partidárias dos prefeitos, nível de organização da burocracia e capacidade de financiamento dos municípios. Nesse sentido, para melhor compreendermos as variáveis que afetam a distribuição de recursos nas políticas públicas de esporte e lazer, ainda temos um longo caminho a percorrer.

\section{REFERÊNCIAS}

ABRUCIO, F. L; FRANZESE, C. Federalismo e políticas públicas: o impacto das relações intergovernamentais no Brasil. Tópicos de economia paulista para gestores públicos, v. 1, p. 13-31, 2007.

ALMEIDA, M. H. T. Federalismo e políticas sociais. Revista Brasileira de Ciências Sociais, São Paulo, v. 10, n. 28, p. 88-108, 1995.

ARRETCHE, M. Federalismo e igualdade territorial: uma contradição em termos? Dados, Rio de Janeiro, v. 53, n. 3, p. 587-620, 2010.

- Federalismo e políticas sociais no Brasil: problemas de coordenação e autonomia. São Paulo em Perspectiva, São Paulo, v.. 18, n. 2, p. 17-26, 2004.

. Financiamento federal e gestão local de políticas sociais: o difícil equilíbrio entre regulação, responsabilidade e autonomia. Ciência e Saúde Coletiva, v. 8, n. 2, p. 331-345, 2003.

BERCOVICI, G. O federalismo no Brasil e os limites da competência legislativa e administrativa: memórias da pesquisa. Revista Jurídica da Presidência, v. 10, n. 90, p. 01-18, 2011.

BRASIL. Constituição (1988). Constituição da República Federativa do Brasil, 1988. Brasília: Senado Federal, Centro Gráfico, 1988. 292p.

. Ministério do Planejamento, Orçamento e Gestão. Portaria n. ${ }^{\circ} 42$, de 14 de abril de 1999. Diário Oficial [da] República Federativa do Brasil, Brasília, DF, 14 
abr. 1999. Disponível em: ftp://ftp.fnde.gov.br/web/siope/leis/P42_MPOG_14041999.pdf. Acesso em: 05 abr. 2017.

Lei complementar $\mathrm{n}^{\mathrm{o}} 101$, de 4 de maio de 2000. Estabelece normas de finanças públicas voltadas para a responsabilidade na gestão fiscal e dá outras providências. Diário Oficial [da] República Federativa do Brasil, Brasília, DF, 4 maio 2000. Disponível em: https://www.planalto.gov.br/ccivil_03/leis/lcp/lcp101.htm . Acesso em: 19 mar. 2017.

. Lei n. ${ }^{\circ}$ 4.320, de 17 de março de 1964. Estatui Normas Gerais de Direito Financeiro para elaboração e controle dos orçamentos e balanços da União, dos Estados, dos Municípios e do Distrito Federal. Diário Oficial [da] República Federativa do Brasil, Brasília, DF, 17 mar. 1964. Disponível em: http://www.planalto.gov.br/ccivil_03/leis/14320.htm. Acesso em: 20 mar. 2017.

CASTRO, S. B. E. de. Políticas públicas para o esporte e lazer e o ciclo orçamentário brasileiro (2004-2011): prioridades e distribuição de recursos durante os processos de elaboração e execução orçamentária. 382 f. Tese (Doutorado em Educação Física) - Universidade Federal do Paraná, Curitiba, 2016.

CATAIA, M. Federalismo brasileiro. As relações intergovernamentais analisadas a partir das transferências voluntárias (união/municípios). Revista Geográfica de América Central, v. 2, n. 47E, 2011.

FERRAZ Jr., T. S. Normas gerais e competência concorrente. Uma exegese do art. 24 da Constituição Federal. Revista da Faculdade de Direito, Universidade de São Paulo, v. 90, p. 245-251, 1995.

GIL, A. C. Como elaborar projetos de pesquisa. 4. ed. São Paulo: Atlas, 2007.

GOMES, D. A. O desporto e a Constituição da República Federativa do Brasil de 1988. Contribuição ao estudo do direito desportivo. Jus Navigand, p. 1-28, 2010.

GOMES, G. M; DOWELL, M. C. Descentralização política, federalismo fiscal e criação de municípios: o que é mau para o econômico nem sempre é bom para o social. Texto para Discussão n. 706, IPEA, Brasília, 2000.

HORTA, R. M. Repartição de Competências na Constituição de 1988. Revista da Faculdade de Direito da UFMG, n. 33, p. 249-274, 1991.

KLEINKE, M. de L. U. et al. Federalismo e políticas sociais. Revista Paranaense de Desenvolvimento, v. 117, n. 117, p. 7-28, 2009.

MACHADO, P. A. L. Competência comum, concorrente e supletiva em matéria de meio ambiente, Revista de informação legislativa, v. 33, n. 131, p. 167-174, jul./set. 1996.

MUKAI, T. Competências dos entes Federados na Constituição de 1988. Revista de Direito Administrativo, v. 184, p. 86-96, 2001. 
PRADO, S.. Transferências fiscais e financiamento municipal no Brasil. Relatório de Pesquisa Descentralização Fiscal e Cooperação Financeira Intergovernamental. EBAP/Fundação Konrad Adenauer, 2001.

REVERDITO, R. S. et al. O Programa Segundo Tempo (PST) em municípios brasileiros: indicadores de resultado no macrossistema. Journal of Physical Education, v. 27, n. 1, p. 27-54, 2016.

SABATIER, P. Top-down and Botton up approaches to implementation research: a critical analysis and suggested synthesis. Journal of Public Policy, v.6, n. 2, 1985.

SANTOS, E. S. As coalizões e os partidos políticos na difusão do programa segundo tempo. Licere, v. 15, n.3, p. 1-26, 2012.

SANTOS, E. S. Ambiente institucional e difusão do Programa Segundo Tempo: uma análise da difusão regional de 2005 a 2009. Pensar a Prática, v. 16, n. 1, p. 35-53, 2013.

; ANDRADE, J. C. S.; SANTOS, R. S. Programa Segundo Tempo e o papel das prefeituras em sua difusão. Pensar a Prática, v. 17, n. 4, p. 36-42, 2014.

; CANAN, Felipe; STAREPRAVO, Fernando Augusto. Investments in the sport and leisure function by municipalities In Bahia from 2002 to 2011. Journal of Physical Education, v. 29, p. 1-10, 2018

SANTOS, E. S.; NOGUEIRA, R. Avaliação da Política Pública de Esporte Educacional: o Caso do Programa Segundo Tempo/ME na Região Sul da Bahia. Revista Interdisciplinar de Gestão Social, v. 5, n. 1, p. 89-105, 2016.

; STAREPRAVO, F. A; SOUZA NETO, M. S. Programa Segundo Tempo e o vazio assistencial na região Nordeste. Movimento, Porto Alegre, v. 21, n. 3, p. 759-771, 2015 .

.; FREITAS, A. L. C. O direito ao desporto: justiça social e políticas públicas. Direitos Fundamentais \& Justiça, v. 9, p. 139-157, 2015.

SANTOS, F. C. Procurando o lazer na constituinte: sua inclusão como direito social na Constituição de 1988. Movimento, v. 20, p. 1305-1327, 2014.

SECCHI, L. Políticas públicas: conceitos, esquemas de análise, casos práticos. São Paulo: Cengage Learning, 2013.

SOARES, M. M.; MELO, B. G. Condicionantes políticos e técnicos das transferências voluntárias da União aos municípios brasileiros. Revista de Administração Pública, v. 50, n. 4, p. 539-561, 2016.

\section{Endereço dos Autores:}

Edmilson Santos dos Santos 
Fernanda Gimenez Milani, Riller Silva Reverdito e

Fernando Augusto Starepravo

Universidade Federal do Vale do São Francisco

Colegiado de Educação Física

Av. José de Sá Maniçoba, S/N - Centro

Petrolina - PE - 56.304917

Endereço Eletrônico: edmilson.santos@univasf.edu.br

Fernanda Gimenez Milani

Rua Vila dos Remédios, ${ }^{\circ} 14$, Apartamento 501 - Jardim Social

Maringá - PR - 87.010-040

Endereço Eletrônico: fernandagmilani@gmail.com

Riller Silva Reverdito

Universidade do Estado de Mato Grosso

Faculdade de Ciências da Saúde

Curso de Educação Física

Cidade Universitária, Bloco II, Educação Física, $\mathrm{n}^{\mathrm{o}} \mathrm{s} / \mathrm{n}$ - Santos Dumont

Cáceres - MT -78.200-000

Endereço Eletrônico: rsreverdito@gmail.com

Fernando Augusto Starepravo

Universidade Estadual de Maringá

Centro de Ciências Biológicas

Departamento de Educação Física

Avenida Colombo, 5.790 - Campus Universitário - Centro

Maringá - PR - 87.020900

Endereço Eletrônico: fernando.starepravo@hotmail.com 